\title{
Vaccina Calmette-Guérin
}

\author{
Trabalho lido na Sociedade Arnaldo \\ Vieira de Carvalho pela doutorando \\ Nelson de Sousa Campos.
}

$\mathbf{D}$

ESDE os tempos immediatamente subsequentes á descoberta do bacillo da tuberculose por Koch, varios experimentadores vêm tentando, e ainda continuam, o modo de conferir a immunidade contra ella, quer empregando para a vaccinação raças attenuadas de bacillos vivos, pelo aquecimento ou pelos meios chimicos, quer usando bacillos mortos ou productos desses mesmos bacillos. Alguns autores conseguiram obter certa immunidade dos animaes assim tratados, porém, fugaz, desapparecendo após algumas semanas.

Em 1906, Calmette-Guérin e outros começaram seus estudos nesse assumpto, tão paciente e criteriosamente encaminhados que, na hora actual, parece estar esse problema em grande parte resolvido, ou pelo menos, o bastante elucidado para se obter delle os primeiros resultados.

A primeira tentativa nesse sentido foi feita por Koch, com a tuberculina por elle descoberta, abandonada logo depois, não só pelos resultados nullos, como pela sua toxidez.

Em seguida, empregaram-se os bacillos mortos pelo calor, que conferiam aos animaes, além de uma resistencia embora pequena, uma tendencia para a evolução chronica das infecções virulentas, que os affectassem.

Ao mesmo tempo, o emprego dos bacillos vivos virulentos, ou de virulencia expontaneamente attenuada, deu resultados mais animadores, e isso pela injecção endovenosa, repetida duas vezes e com intervallo de tres mezes entre uma injecção e a outra, de uma cultura de bacillos humanos. Essas experiencias foram feitas em bezerros.

Esse methodo foi usado com grandes esperanças e algum resultado na Allemanha, França, Italia, Estados Unidos e outros paizes, cujos rebanhos soffreram eśsa vaccinação. Não foi entretanto tentado para o homem, porque desde logo uma objecção séria se levantou, qual a de bacillos de origem humana inoculados permanecerem vivos e virulentos nos ganglios, podendo, não de raro, accarretar a evolução aguda da tuberculose, como foi verificada no cobayo. 
Ferran, deante dos insuccessos precedentes, recorreu a outros meios, para obter essa immunidade, creando uma curiosa theoria toda sua. Ferran acredita que a tuberculose pode ser produzida por differentes bacterias, que são ora acido-resistentes, ora não acidoresistentes, derivando sempre do bacillo de Koch por "mutações bruscas" que modificam seus caracteres de cultura e de virulencia, tornando-se microbios saprophytas, bacterium coli.

E, com a "bacteria alpha" Ferran obteve a vaccina "anti-alpha" capaz de impedir o desenvolvimento do bacillo tuberculoso verdadeiro, mas que - "não protege os animaes contra a acção das toxinas lipoides do bacillo de Koch virulento, nem contra a dos tecidos tuberculosos ou do pús ganglionar"

Apezar disso, a vaccina anti-alpha tem sido injectada, por Ferran e seus collaboradores, em milhares de individuos, de todas as edades e condições sociaes, embora o mesmo Ferran affirme: "A vaccina anti-alpha não cura a tuberculose confirmada, isto é, a tuberculose com tuberculos, porque age sobre as lesões produzidas pelas toxinas lipoides do bacillo de Koch, que produzem os tuberculos; modifica, porém, favoravelmente e melhor que nenhum outro remedio, as inflammações peri-tuberculosas, produzidas pelas toxinas albuminoides das bacterias alpha, analogas ás toxinas albuminoides do bacillo de Koch"

E' fóra de duvida que Ferran palmilhava uma theoria erronea. Os resultados por elle obtidos, talvez se devam á acção das proteinas microbianas, augmentando a leucocytose e a consequente phagocytose, agindo pode-se dizer, como proteino ou bacterio-therapia.

Entretanto, a immunidade anti-tuberculosa é um facto innegavel, pois é uma observação firmada que os individuos portadores de adenites tuberculosas suppuradas e curadas ficam em parte refractarios a novas contaminações. Marfan já em 1886 tinha affirmado: "O lupus e a escrophula, curados, protegem contra uma nova infecção tuberculosa" - e mesmo Koch, em 1891, já tinha observado que os animaes tuberculosos e sãos reagem diversamente a uma inoculação do bacillo, observação que foi o ponto de partida para a descoberta do "phenomeno de Koch" - Varios autores, principalmente Calmette e os collaboradores que ao seu lado militam, dedicando-se a este assumpto, chegaram á conclusão de que essa immunidade, assim como aquella conferida por contaminações precoces e benignas, era devida á presença no organismo, de bacillos em vida latente.

Essas observações induziram esses autores a tentar uma impregnação tão precoce quanto possivel de todo o systema lymphatico do organismo - a tuberculose sendo essencialmente uma molestia do systema lymphatico - com bacillos tuberculosos vivos, mas privados de virulencia.

Para isso, começaram por empregar bacillos vivos de origem equina, fracamente tuberculigenos e quasi desprovidos de virulencia 
para o cobayo. Webbs e Williams, nos Estados Unidos, empregaram, ao mesmo tempo, o bacillo aviario com resultados negativos, pela toxidez que ainda apresentava.

Dahi a procura de um estado do bacillo tuberculoso, que fosse realmente privado de virulencia para todas as especies animaes.

Para a obtenção desse estado do virus tuberculoso no organismo, esses autores idealizaram e obtiveram um bacillo, que, embora vivo, era hereditariamente privado de suas propriedades tuberculigenas, conservando ainda, porém, a sua aptidão de conferir ao organismo uma immunidade relativa a novas infecções, a que elle venha a ser submettido.

Tal é o conceito fundamental que dirigiu a escola de Calmette, durante mais de vinte annos, e que terminou pela descoberta de um processo de vaccinação, por meio de bacillos vivos, porém alterados na sua funcção primordial, que é a de formar tuberculos.

Consiste esse processo na repicagem quinzenal de uma cultura de bacillos, em meio extremamente alcalino, constituida por bile pura de boi, glycerinada a $5 \%$, perdendo o bacillo depois de um determinado numero de repicagens, a pouco e pouco, as suas propriedades tuberculigenas. Depois de 230 culturas successivas, para o que os autores levaram treze annos, sempre no mesmo meio, e á mesma temperatura, $38^{\circ}$, mostrou Calmette que o bacillo tinha perdido toda propriedade tuberculigena e toda virulencia, não só para os animaes de laboratorio, como o homem, sem comtudo ter perdido as suas propriedades antigenas. Assim é que transplantados para um meio de cultura habitual, elle continuava a determinar, entre os animaes aos quaes se o injectava, a formação de anti-corpos, postos em evidencia pela reacção da fixação do complemento, de Bordet-Gengou.

Este bacillo, denominado BCG (Bacillo-Calmette-Guerin), embora reinoculado diversas vezes em animaes de Laboratorio, de qualquer edade, mostrou ser perfeitamente toleravel por todos os animaes tuberculisaveis, em dose massiças, e mesmo por inoculações por via endovenosa.

Foi aproveitando-se dessa propriedade que se tentou conferir aos animaes jovens, indemnes de tuberculose pré-existente, a propriedade de tolerar as reinfecções, produzindo-lhes uma verdadeira vaccinação. Esta vaccinação, confere-lhes uma resistencia contra a infecção tuberculosa virulenta, emquanto perdurarem no organismo esses bacillos vaccinas, que são eliminados pelas vias emunctoriaes naturaes.

Calmette é apologista da via digestiva, como porta de entrada do virus tuberculoso, principalmente na infancia, o que entretanto não é para surprehender, dada a facilidade com que a mucosa intestinal do recem-nascido, absorve microbios e toxinas, propriedade que perde algumas semanas após o nascimento. 
Disse, de Berlim, mostrou que entre os recem-nascidos, as cellulas epitheliaes do intestino são inteiramente protoplasmaticas, e que a verdadeira mucosa, só apparece alguns dias depois do nascimento. Assim, diz elle, - "nos primeiros dias de vida, o intestino é permeavel não somente aos bacillos, mas tambem ás substancias albuminoides, ás toxinas e ás anti-toxinas" - Isso vem nos demonstrar, não somente quão facil é a contaminação nessa época da vida, e tambem que é nessa edade, que melhores resultados poderão ser tirados da vaccinação, porque uma vez immunisados, os pequenos animaes poderão facilmente reagir ás infecções posteriores, a que fatalmente hão de estar sujeitos.

E' por conseguinte na infancia que esta infecção se processa, e, para os filhos de mães tuberculosas, é indiscutivelmente nos primeiros mezes que elles se contaminam, sendo excepcional que elles possam chegar á edade adulta, sem se infeccionar, sndo que a tuberculose do adulto, para alguns autores, nada mais seja que o acordar de uma contaminação apanhada na infancia. Portanto, é justo e racional basearmos a prophylaxia anti-tuberculosa na defesa da infancia pela vaccinação de Calmette-Guérin.

E este methodo tem provado admiravelmente.

Entre os pequenos animaes de laboratorio, coelhos e cobayos, os primeiros que receberam esta vaccina, os resultados foram tão satisfactorios, que a vaccinação dos animaes em escala superiores, gado bovino e macacos, foi feita,, e desde 1921, que ella é praticada nos recem-nascidos, não só em França como em muitos outros paizes.

A pratica tem demonstrado que a vaccinação por via buccal, principalmente em animaes novos, tem dado melhores resultados que pelas outras vias: sub-cutanea, endo-venosa ou intra-peritoneal.

Os primeiros ensaios foram feitos nos pequenos animaes de laboratorio, coelhos e cobayos, que receberam, em cinco ou dez doses de dois centigrammos, dez a vinte centigrammos de bacillo-vaccina, por via buccal. Tres mezes depois, com animaes testemunhos, receberam uma inoculação de um milligrammo de bacillo virulento. Os coelhos e cobayos vaccinados sobreviveram sempre aos testemunhos, que morreram por tuberculose miliar, antes de 6 mezes.

Tentada entre os bovideos, nas primeiras semanas de vida, notou-se que os premuia pelo espaço de 15 mezes mais ou menos, embora conservados em meios expostos aos contagios naturaes, nada modificando de seu habitat, e revaccinados cada 12 mezes, permaneceram sempre em perfeita saúde.

Até Janeiro de 1926, o total dos bezerros vaccinados, em diversos paizes, segundo o "Bureau of Animal Indǔstry" era de 3.051 e, entre esses animaes, criados nos seus habitats normaes, nenhum caso de tuberculose foi verificado. 
As reacções pela tuberculina se comportavam de um modo bastante variavel, mas, por certos factos, até agora não bem precisados, os autores eram de opinião que ellas além de não terem a mesma significação que nos animaes não vaccinados, ellas - "não são inoffensivas para os animaes immunisados pelo BCG, sensibilisando-os vis á vis de infecções virulentas artificial ou accidentalmente realisadas"

A vaccinação dos macacos, feita sob a direcção de Wilbert, no Instituto Pasteur de Kindia, de 1923 a 1924, nos forneceu dados bastante interessantes.

Quinze chipanzés e 59 pithécianos, agrupados em uma mesma gaiola, foram divididos da seguinte maneira: 3 chipanzés foram vaccinados, por via sub-cutanea ou ora, com fortes doses de bacillos vaccinas; 5 foram infectados, e 7 conservados como testemunhos; dos pithécianos, 19 receberam a vaccina, 20 foram infectados, e 20 mantidos como testemunhos.

Um anno após, verificou-se que os resultados não podiam ser mais persuasivos.

Todos os animaes testemunhos e infectados, tinham morrido de tuberculose sob diversas formas, ao passo que dos chipanzés vaccinados, todos os 3 sobreviveram, permanecendo em bôa saúde, embora em cohabitação com seus companheiros infectados e testemủnhos. E sobre os 19 pithécianos vaccinados, apenas 6 sobreviveram, e dos 11 fallecidos, nenhum apresentou á autopsia a menor lesão tuberculosa.

A experimentação em macacos, foi, pois, bastante demonstrativa e isso não só quanta á inocuidade da vaccina, pois em alguns casos foram usadas doses consideraveis de cultura, sem o menor accidente, como tambem quanto á sua efficacia, na immunização contra a infecção pelo contacto intimo e prolongado com animaes contagiantes.

Assim provada, a vaccinação foi tentada no homem, dentro de certas precauções entretanto, quaes a de ser feita de preferencia nos filhos de tuberculosos, nos seus primeiros dias de vida, ou em creanças sem o terreno tuberculoso em outras edades, certos sempre de que estavam indemnes de toda infecção bacillar. E essa é uma questão capital num serviço de vaccinação. A não existencia de um contagio anterior, é um dos factores para o bom resultado pratico final, assim como a vaccinação nos primeiros dias de vida, época em que o poder de absorpção do intestino é maior, é uma pratica que deverá sempre ser seguida.

Foi em Julho de 1921 que a primeira creança nascida num meio tuberculoso foi vaccinada nos $3 .^{\circ} 5 .^{\circ}$ e $7 .^{\circ}$ dias de vida, pela ingestão de 2 milligrammos de bacillos-vaccina. Nenhum accidente foi notado, e o seu crescimento se procedeu normalmente.

Essa perfeita tolerancia induziu os experimentadores a augmentarem a dóse de vaccina, chegando até um centigrammo pró dose, 
num total de 1 bilhão e 200 milhões de bacillos-vaccina, e isso sempre com perfeita tolerancia dos vaccinados.

De 1922 para cá, a vaccina tem sido applicada no maior numero possivel de creanças, sendo que, nesse anno, uma primeira série de 217 creanças soffreu a vaccinação nos 10 primeiros dias de vida; 39 dessas creanças foram, por mudança ou por qualquer outra causa, perdidas de vista. Das 178 restantes e observadas no seu desenvolvimento até 1924 , apenas $5 \%$ ou 9 , vieram a fallecer e isso por causas diversas e em nenhuma provada a tuberculose, e as demais 169 tiveram um desenvolvimento regular.

A vaccinação continuou, e de $10^{\circ}$ de Julho de 1924 até $10^{\circ}$ de Janeiro de 1926, já 5.183 creanças tinham recebido em França a vaccinação B.C.G., e isso sem o menor accidente de qualquer especie. Desse numero, 1.317 já o foram ha mais de 6 mezes e por conseguinte sufficientemente observadas, o resultado controlado, podendo ser commentado.

São dos Annaes do Instituto Pasteur de Paris as seguintes observações que reproduzimos:

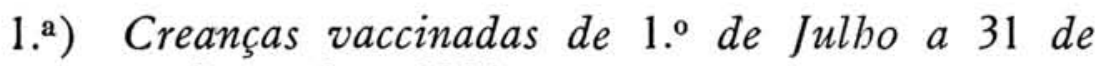
Dezembro 1924:

a) vivas até $1 .^{\circ}$ Janeiro de 1926 :

das quaes:

Em contacto com mãe bacillifera:

" " " pae e mãe bacilliferos

" " " " collateraes ou estranhos

bacilliferos:

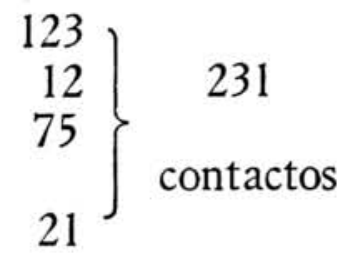

Sem indicaçãa de contactos:

218

b) mortas de molestias diversas não tuberculosas:

mortas de molestias presumidas tuberculosa:

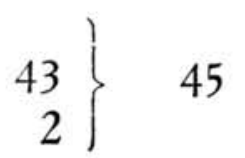

2. $\left.{ }^{a}\right)$ Creanças vaccinadas de $1 .^{\circ}$ Janeiro a 30 de Junbo 1925:

a) vivas em $1.0^{\circ}$ Janeiro 1926 :

691

das quaes:

Em contacto com mãe bacillifera:

, ," , pae bacillifero:

, " , ", , e mãe bacilliferos:

" " " collateraes ou estranhos

bacilliferos:

$168 \mid 355$

Sem indicação de contactos: 
b) mortas de molestias diversas não tuberculosas:

mortas de molestias presumidas tuberculosa:

Esse quadro é bastante demonstrativo: por elle vemos que dessas 1.317 creanças, 586 estavam em contacto director com bacilliferos, muitas dellas filhas de progenitores tuberculosos, heredo-predispostas por conseguinte, e que estariam fatalmente condemnadas a se contaminar, e no entretanto, $6,12,18$ mezes passados, gozam saúde, parecem indemnes de contaminação.

Do total dessas creanças, isto é, em 1.317 creanças, num espaço de tempo de 18 mezes, apenas 107 falleceram, das quaes 96 ou $7,2 \%$ de molestia não tuberculosa e 11 ou $0,7 \%$ presumivelmente de tuberculose.

A explicação desses 11 obitos é possivel, considerando-se que a tuberculose congenita, embora rara, existe, pela passagem através da placenta do virus tuberculoso, sob sua forma filtravel. Parece provavel que esta contaminação fotal se dê e que só ella poderá explicar certas anemias congenitas, certas hypotrophias com alterações ganglionares, em recem-nascidos.

Mas a raridade de taes casos não é sufficiente para desvalorisar a vaccina e condemnar o seu emprego, pois os resultados obtidos a justificam sobejamente.

E mais ainda: se calcularmos a porcentagem de fallecimento por tuberculose, 11, sobre o total das creanças em meio bacillifero, 586, vemos que ella é apenas de 1,8\%

$\mathrm{Na}$ Belgica, Malvaz e Von Beneden vaccinaram, pela mesma época, 107 lactantes, dos quaes 97 foram regularmente seguidas: nenbum succumbiu á affecção presumivelmente tuberculosa, muito embora 64 dentre elles, tenham sido criados por mães bacillosas.

Mais recentemente ainda, os Annaes do Instituto Pasteur de Paris, no seu numero de Março do corrente anno, nos trazem as seguintes notas e o seguinte quadro sobre a vaccina B. C. G.:

"Até $1 .^{\circ}$ de Janeiro de 1927 o numero total de creanças vaccinadas pelo B. C. G. em França, desde $1 .^{\circ}$ de Julho de 1924 era de 21.200. Mas a observação visou de preferencia as creanças vaccinadas ha mais de um anno, as creanças de mães tuberculosas ou creadas em ambiente contaminado familiar, porque só estas, permittem comparar seus resultados com o de um numero igual ou maior de creanças nascidas ou criadas nas mesmas condições de contagio e não vaccinadas. Foram observadas nessas condiçôes 982 creanças, já vaccinadas 12 até 30 mezes antes - 1 anno a 2 annos e meio, - sendo que desse numero somente 13 foram separadas do fóco contagiante, o que reduz esse numero para 969. Para essas 969 creanças tuberculisaveis, heredopredispostas, a mortalidade geral é de $8,1 \%$ e a mortalidade presu- 
mida de tuberculose é de $0,7 \%$. Na mortalidade geral ha 31 casos de morte por causas não especificadas. Mesmo attribuindo esses casos á tuberculose, nós temos a taxa de 3,9\%, cifra ainda consideravelmente inferior á mortalidade media das creanças da mesma cathegoria e não vaccinadas e que é de $32 \%$ em França. E assim conclue Mr. Moine, organisador do serviço de estatistica do Serviço contra a Tuberculose em França:

- "Deante desses resultados, pode-se affirmar que a mortalidade por tuberculose é para as creanças vaccinadas, ha mais de um anno, visinha de $1 \%$, emquanto para as não vaccinadas ella é de $26 \%$ "

Eis o quadro de Mr. Moine:

\begin{tabular}{|c|c|c|c|c|c|c|c|c|}
\hline \multirow{2}{*}{$\begin{array}{c}\text { CLASSIFICAÇÃO } \\
\text { DOS } \\
\text { CONTACTOS }\end{array}$} & \multicolumn{2}{|c|}{ Vaccinados } & \multirow[b]{2}{*}{ Total } & \multirow{2}{*}{$\begin{array}{l}\text { Fallecid. } \\
\text { por mo } \\
\text { lest. pre- } \\
\text { sumidas } \\
\text { tuberc. }\end{array}$} & \multirow{2}{*}{$\mid \begin{array}{c}\text { Mortes } \\
\text { por } \\
\text { moles- } \\
\text { tia não } \\
\text { tubere. }\end{array}$} & \multirow{2}{*}{$\begin{array}{c}\text { Revae- } \\
\text { cinação } \\
\text { após o } \\
1.0 \\
\text { anno }\end{array}$} & \multirow{2}{*}{$\begin{array}{l}\text { Porcent. } \\
\text { fallecimen- } \\
\text { los por } \\
\text { tubercu. }\end{array}$} & \multirow{2}{*}{$\begin{array}{l}\text { Porcent. } \\
\text { fallecimen- } \\
\text { tos por } \\
\text { outras mo- } \\
\text { lestias }\end{array}$} \\
\hline &  & 焉 & & & & & & \\
\hline $\begin{array}{l}\text { Mãe tuberculosa } \\
\text { Pae tuberculoso } \\
\text { Pae e mãe tuberculosos } \\
\text { Collacteraes tubeacul. } \\
\text { Contactos varios }\end{array}$ & $\begin{array}{r}269 \\
264 \\
31 \\
82 \\
236\end{array}$ & $\begin{array}{r}34 \\
24 \\
4 \\
4 \\
21\end{array}$ & $\begin{array}{r}303 \\
288 \\
35 \\
86 \\
257\end{array}$ & $\begin{array}{l}2 \\
3 \\
1 \\
1\end{array}$ & $\begin{array}{r}15 \\
12 \\
4 \\
3 \\
38\end{array}$ & $\begin{array}{r}23 \\
32 \\
6 \\
3 \\
36\end{array}$ & $\begin{array}{r}0,66 \% \\
1: 04 \% \\
0 \% \\
1,16 \% \\
0,39 \%\end{array}$ & $\begin{array}{r}4,94 \% \\
4,17 \% \\
11,43 \% \\
3,48 \% \\
14,79 \%\end{array}$ \\
\hline Total & 882 & 87 & 969 & 7 & 72 & 100 & $0 \times 71 \%$ & $7,43 \%$ \\
\hline $\begin{array}{l}\text { Nascidos de mães tu- } \\
\text { berculosas. mas separa- } \\
\text { das desde o nascimento }\end{array}$ & 12 & 1 & 13 & 1 & 一 & - & & \\
\hline
\end{tabular}

O Dr. Y Biraud do Instituto de Hygiene da Faculdade de Medicina de Paris, sobre 1.877 fichas de creanças vaccinadas de 1924 a 1926, e em contacto com pessoas tuberculosas, achou a mortalidade geral de $7,6 \%$ no decurso de um anno após a vaccinação e $1,8 \%$ no decurso do $2 .^{\circ}$ anno. A mortalidade por tuberculose para esse autor foi de $1,55 \%$

E' tão concludente este resultado que Calmette assim termina um de seus trabalhos a esse respeito: - "a vaccinação dos recemnascidos pelo B.C.G. permitte salvaguardar pelo menos $93 \%$ das creanças, que, sem este meio de immunização, succumbiriam fatalmente de tuberculose nos primeiros annos de șua existencia" 